\title{
Turmeric Oil Mediated Green Synthesis of Silver Nanoparticles and their Antioxidant Activity
}

\author{
Varusha Sharon Christopher ${ }^{1}$, Anitha Roy², Shanmugam Rajeshkumar ${ }^{3}$ \\ 1, 2,3 Department of Pharmacology, Saveetha Dental College, \\ Saveetha Institute of Medical and Technical Sciences, Chennai, Tamil Nadu, India.
}

\section{BACKGROUND}

The number of medical applications of silver nanoparticles is constantly increasing due to their high bactericidal properties coupled with low toxicity towards living cells. Because of this expanding use of silver nanoparticles, novel methods of synthesis have been developed in order to achieve nanoparticles preparation through inexpensive and environmentally friendly process. ${ }^{1}$ Biogenic synthesis of silver nanoparticles is an approach that meets those requirements. Nanoparticles are an intermediate between bulk materials and individual atoms with unique properties. Nanoparticles have been employed in various fields such as catalysis, ceramics, drug delivery and diagnostics and therapies of oncology. ${ }^{2}$ Several studies have described the controlled synthesis of metal nanoparticles of different sizes and shapes mediated by bio molecules, which is nontoxic and minimises environment damage.

Antioxidants have been widely used as additive to provide protection against oxidative degradation of foods. ${ }^{3}$ Although many synthetic chemicals, such as phenolic compounds are found to be strong radical scavengers, they usually have serious side effects. ${ }^{4}$ In view of this, antioxidant substances obtained from natural sources will be great interest.

Turmeric is extensively used as spice, as a colouring agent for textiles, pharmaceuticals, confectionary and cosmetics. ${ }^{5}$ In Indian system of medicine, turmeric is used in stomach-ache, as a blood purifier, carminative, appetiser and tonic.5,6 Turmeric is also used in drugs against cancer, dermatitis, AIDS (Acquired Immuno-Deficiency Syndrome) and high cholesterol level. ${ }^{7}$ During the course of this study, we have synthesized silver nanoparticles using turmeric oil and characterised them using UV-vis spectroscopic analysis and checked for their antioxidant activity.

\section{SYNTHESIS OF SILVER NANOPARTICLES}

In this descriptive study, the synthesis of the silver nanoparticles is been done with green synthesis method. A fresh turmeric oil sample was collected, and added to 50 $\mathrm{mL}$ of $1 \times 10-3 \mathrm{M}$ silver nitrate and incubated in the room temperature. Formations of grey colour with turmeric oil mixture after $60 \mathrm{~min}$ indicates the silver nanoparticles synthesis. The silver nanoparticles thus obtained was spectrometrically recognised with UV-Vis spectrophotometer under the wavelength of $300-600 \mathrm{~nm}$.

\author{
Corresponding Author: \\ Dr. Anitha Roy, \\ Associate Professor, \\ Department of Pharmacology, \\ Saveetha Dental College, \\ Saveetha Institute of Medical \\ and Technical Sciences, Chennai, \\ Tamilnadu, India. \\ E-mail: anitharoy2015@gmail.com
}

DOI: $10.14260 / j e m d s / 2021 / 121$

How to Cite This Article:

Christopher V.S, Roy A, Rajeshkumar S. Turmeric oil mediated green synthesis of silver nanoparticles and their antioxidant activity. J Evolution Med Dent Sci 2021;10(08):558-561, DOI: 10.14260/jemds/2021/121

Submission 25-01-2020,

Peer Review 12-12-2020,

Acceptance 18-12-2020,

Published 22-02-2021.

Copyright (C) 2021 Varusha Sharon Christopher et al. This is an open access article distributed under Creative Commons Attribution License [Attribution 4.0 International (CC BY 4.0)] 
The Nitric Oxide free radical scavenging activity of nanoparticle was also determined by the method of Rajeshkumar 2017. Typically, different concentration (2 - 10 $\mu \mathrm{g} / \mathrm{mL}$ ) of plant extract was mixed with $1 \mathrm{~mL}$ of $0.1 \mathrm{mM} \mathrm{DPPH}$ in methanol solution and $450 \mu \mathrm{l}$ of $50 \mathrm{mM}$ Tris- $\mathrm{HCl}$ (Hydrochloric Acid) buffer (pH 7.4) and incubated for $30 \mathrm{~min}$. After incubation, the reduction in the number of DPPH free radicals was measured based on the absorbance at $517 \mathrm{~nm}$. BHT was used as controls. The percent inhibition was calculated from the following equation:

$\%$ Inhibition $=$

[Absorbance of control - Absorbance of test sample / Absorbance of control] $\times 100$

The addition of turmeric oil extract to $\mathrm{AgNO}_{3}$ (Silver Nitrate) solution resulted visual colour change from colourless to yellow within 5 min because of Surface Plasmon Resonance (SPR) excitation due to the collective oscillation of free conduction electrons induced by an interacting electromagnetic field which is absent in bulk material indicating the reduction of $\mathrm{Ag}+$ to $\mathrm{Ag} 0$ [Graph 1]. Formation of Ag NPs was further confirmed by UV-Visible spectra by recording the absorption spectrum of the colloidal solution [Graph 1] with a characteristic SPR band at $360 \mathrm{~nm}$ with increasing time. The antioxidant activity of biosynthesized Ag NPs was evaluated by DPPH assay with BHT as the standard [Graph 2]. In the present study, the synthesized Ag NPs showed comparable Nitric Oxide free radical scavenging activity to that of the standard [Graph 3].
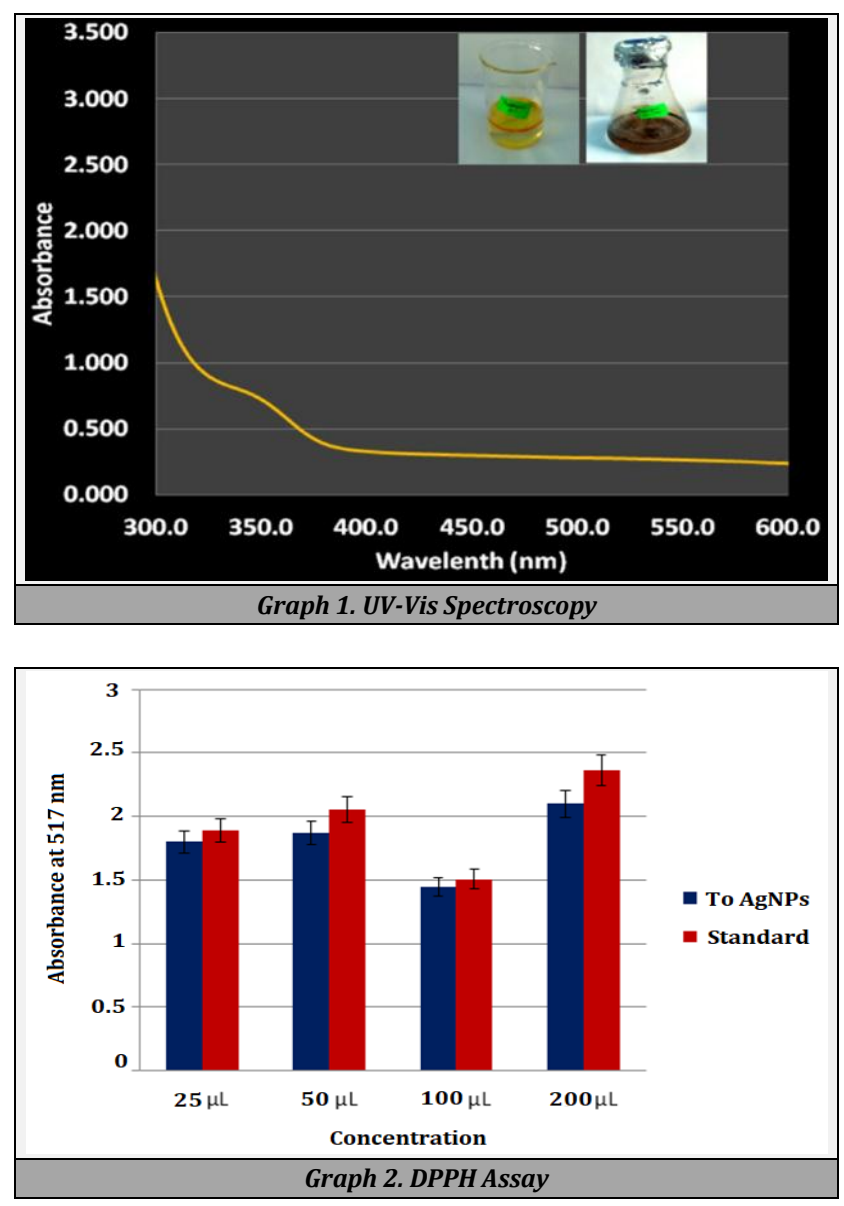

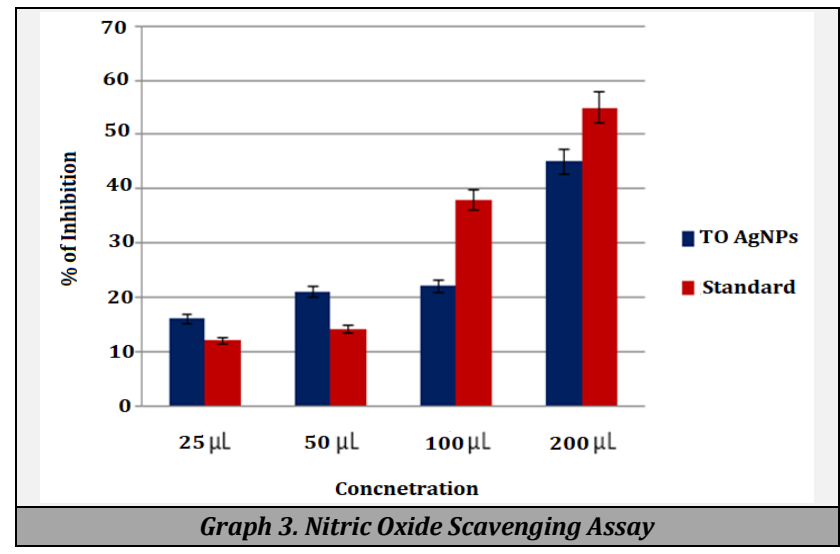

\section{DISCUSSION}

Former studies reported that AgNPs can be synthesised by plants such as Cymbopogon citrates, ${ }^{8}$ Garcinia mangostana bark extract, ${ }^{9}$ Mucuna pruriens seed, ${ }^{10}$ Kalanchoe pinnata leaf, ${ }^{11}$ Acorus calamus root, ${ }^{12}$ Chrysanthemum indicum. ${ }^{13}$ In the current study, aqueous silver ions were reduced to AgNPs after mixing with cumin oil extract followed by incubation. The colour turned yellow to reddish brown and this change in colour has been previously observed by several investigators. ${ }^{14-16}$ These authors suggested that the colour change appeared the study showed dose dependent antioxidant activity by DPPH and Nitric Oxide assay techniques. due to the surface plasmon-resonance of deposited AgNPs.

In the current study, the mechanism by which the turmeric oil could mediate AgNPs may be explained by the higher total phenolics content in it. These plant phenolics are strong antioxidants with high reducing capacity ${ }^{17}$ which can be used for AgNPs synthesis. ${ }^{18}$ The higher content of total phenolic content in turmeric oil extract facilitates the reduction of silver ions to nano-sized silver particles due to the electron donating ability of these phenolic compounds. Furthermore, the quinoid compound produced due to the oxidation of the phenol group in phenolics can be adsorbed on the surface of nanoparticles, accounting for their suspension stabilization. ${ }^{19}$ It is well documented that the phenolic compounds may contribute directly to anti-oxidative action. ${ }^{20}$ This antioxidant activity is attributed to the phenolic contents in plants probably due to their redox properties, which allow them to act as reducing agents, hydrogen donors, and singlet oxygen quenchers. ${ }^{21-25}$

Nanoparticles have application in vascular alteration, especially in endothelial dysfunction related to oxidative stress. ${ }^{26-31}$ This condition can lead to a reduction in nitric oxide (NO) bioavailability, consequently affecting vascular tone regulation and endothelial dysfunction, which is the first phase in the development of cardiovascular diseases. Hence, nanoparticles with antioxidant properties synthesised in the present study may be employed to improve the treatment of cancer, dermatitis, AIDS and high cholesterol level.

\section{CONCLUSIONS}

The present study revealed that silver nanoparticles can be synthesized in a simple, eco-friendly method using turmeric 
oil. These turmeric oil mediated nanoparticles have the potential to be used as an effective antioxidant. Hence, it can be employed in large scale production and may be used for targeted drug delivery in cancer, dermatitis, AIDS and high cholesterol level.

Financial or other competing interests: None.

Disclosure forms provided by the authors are available with the full text of this article at jemds.com.

\section{REFERENCES}

[1] Rajeshkumar S, Bharath LV. Mechanism of plantmediated synthesis of silver nanoparticles - a review on biomolecules involved, characterisation and antibacterial activity. Chem Biol Interact 2017;273:219-27.

[2] Santhoshkumar J, Rajeshkumar S, Kumar SV. Phytoassisted synthesis, characterization and applications of gold nanoparticles- a review. Biochemistry and Biophysics Reports 2017;11:46-57.

[3] Daohua S, Qingbiao L, Ning $\mathrm{H}$, et al. Stability of colloidal silver nanoparticles prepared by bioreduction. Rare Metal Mat Eng 2011;40(1):148-51.

[4] Rastogi L, Arunachalam J. Sunlight based irradiation strategy for rapid green synthesis of highly stable silver nanoparticles using aqueous garlic (Allium sativum) extract and their antibacterial potential. Materials Chemistry and Physics 2011;129(1-2):558-63.

[5] Iravani S. Green synthesis of metal nanoparticles using plants. Green Chemistry 2011;13:2638-50.

[6] Rehana D, Mahendiran D, Kumar RS, et al. Evaluation of antioxidant and anticancer activity of copper oxide nanoparticles synthesized using medicinally important plant extracts. Biomed Pharmacother 2017;89:1067-77.

[7] Ahamed M, Khan MAM, Siddiqui MKJ, et al. Green synthesis, characterization and evaluation of biocompatibility of silver nanoparticles. Physica E LowDimenstional Systems and Nanostrutures 2011;43(6):1266-71.

[8] Azizi S, Mohamad R, Rahim RA, et al. Hydrogel beads bionanocomposite based on kappa-carrageenan and green synthesized silver nanoparticles for biomedical applications. Int J Biol Macromol 2017;104(Pt A):423-31.

[9] Ponarulselvam S, Panneerselvam C, Murugan $\mathrm{K}$, et al. Synthesis of silver nanoparticles using leaves of catharanthus roseus Linn. G. Don and their antiplasmodial activities. Asian Pac J Trop Biomed 2012;2(7):574-80.

[10] Harborne AJ. Phytochemical methods a guide to modern techniques of plant analysis. London: Chapman and Hall 1984.

[11] Rehana D, Mahendiran D, Kumar RS, et al. In vitro antioxidant and antidiabetic activities of zinc oxide nanoparticles synthesized using different plant extracts. Bioprocess Biosyst Eng 2017;40(6):943-57.

[12] Re R, Pellegrini M, Proteggente A, et al. Antioxidant activity applying an improved ABTS radical cation decolorization assay. Free Radic Biol Med 1999;26(910):1231-7.

[13] Jayaprakasha GK, Rao LJ, Sakariah KK. Antioxidant activities of flavidin in different in vitro model systems. Bioorg Med Chem 2004;12(19):5141-6.
[14] Mubarakali D, Thajuddin N, Jeganathan K, et al. Plant extract mediated synthesis of silver and gold nanoparticles and its antibacterial activity against clinically isolated pathogens. Colloids Surf B Biointerfaces 2011;85(2):360-5.

[15] Varadavenkatesan T, Vinayagam R, Selvaraj R. Structural characterization of silver nanoparticles phyto-mediated by a plant waste, seed hull of vinga mungo and their biological applications. J Mol Struct 2017;1149:629-35.

[16] Gulcin I. The antioxidant and radical scavenging activities of black pepper (Piper nigrum) seeds. Int J Food Sci Nutr 2005;56(7):491-9.

[17] Akamine $\mathrm{H}$, Hossain MA, Ishimine $\mathrm{Y}$, et al. Effects of application of $\mathrm{N}, \mathrm{P}$ and $\mathrm{K}$ alone or in combination on growth, yield and curcumin content of turmeric (Curcuma longa L.). Plant Prod Sci 2007;10(1):151-4.

[18] Sathishkumar M, Sneha K, Yun Y. Immobilization of silver nanoparticles synthesized using Curcuma longa tuber powder and extract on cotton cloth for bactericidal activity. Bioresour Technol 2010;101(20):7958-65.

[19] Mauricio MD, Guerra-Ojeda S, Marchio P. Nanoparticles in medicine: a focus on vascular oxidative stress. Oxid Med Cell Longev 2018;2018:6231482.

[20] Rajeshkumar S. Antioxidant activity of characterized silver nanoparticles synthesized using flower extracts of Chrysanthemum indicum. Research Journal of Biotechnology 2017;12(8):38-43.

[21] Vignesh V, Anbarasi KR, Sathiyanarayanan G, et al. Green synthesis of biogenic silver nanomaterials using Raphanus sativus extract, effects of stabilizers on the morphology and their antimicrobial activities, Physicochem. Eng Aspects 2013;12:37-46.

[22] Raveendran P, Fu J, Wallen SL. Completely green synthesis and stabilization of metal nanoparticles. J Am Chem Soc 2003;125(46):13940-1.

[23] Vanaja M, Gnanajobitha G, Paulkumar $K$, et al. Phytosynthesis of silver nanoparticles by cissus quadrangularis: influence of physicochemical factors. Journal of Nanostructures in Chemistry 2013;3:17.

[24] Malarkodi C, Rajeshkumar S, Paulkumar K, et al. Bactericidal activity of bio mediated silver nanoparticles synthesized by Serratia nematodiphila. Drug Invention Today 2013;5(2):119-25.

[25] Gnanajobitha G, Paulkumar K, Vanaja M, et al. Fruit mediated synthesis of silver nanoparticles using vitis vinifera and evaluation of their antimicrobial efficacy. Journal of Nanostructures in Chemistry 2013;3(67):1-6.

[26] Rajeshkumar S. Synthesis of silver nanoparticles using fresh bark of pongamia pinnata and its antibacterial action against gram positive and gram negative pathogens. Resource-Efficient Technologies 2016;2(1):30-5.

[27] Kanagavalli U, Sadiq AM, Sathishkumar, et al. Plant assisted synthesis of silver nanoparticles using boerhaavia diffusa leaves extract and evolution of antibacterial activity. Research J Pharmacy and Technology 2016;9(8):1064-8.

[28] Asha S, Asha A, Rajeshkumar S. Evaluation of phytochemical constituents and antimicrobial activity of silver nanoparticle synthesized ipomoea nil against selected pathogens. Asian Journal of Pharmaceutical and Clinical Research 2017;10(3):1-5. 
[29] Asha S, Thirunavukkarasu P, Rajeshkumar S. Green synthesis of silver nanoparticles using mirabilis jalapa aqueous extract and their antibacterial activity against respective microorganisms. Research Journal of Pharmacy Technology 2017;10(3): 811-7.

[30] Kumar SV, Karpagambigai S, Rosy PJ, et al. Phyto-assisted synthesis of silver nanoparticles using solanum nigrum and antibacterial activity against salmonella typhi and staphylococcus aureus. Mechanics, Materials Science \& Engineering 2017;9(1).

[31] Shanmugam R. Antioxidant activity of characterized silver nanoparticles synthesized using flower extracts of chrysanthemum indicum. Research Journal of Biotechnology 2017;12(8):38-43. 